\title{
Prevalence and Severity of Depression and Its Association with Substance Use in Jimma Town, Southwest Ethiopia
}

\author{
Andualem Mossie, ${ }^{1}$ Dagmawi Kindu, ${ }^{2}$ and Alemayehu Negash ${ }^{3}$ \\ ${ }^{1}$ Department of Biomedical Sciences, College of Health Sciences, Jimma University, Ethiopia \\ ${ }^{2}$ College of Health Sciences, Debre Tabor University, Ethiopia \\ ${ }^{3}$ Department of Psychiatry, College of Health Sciences, Jimma University, Ethiopia
}

Correspondence should be addressed to Andualem Mossie; andualemm2000@gmail.com

Received 20 November 2015; Revised 15 February 2016; Accepted 16 February 2016

Academic Editor: Martin Alda

Copyright (C) 2016 Andualem Mossie et al. This is an open access article distributed under the Creative Commons Attribution License, which permits unrestricted use, distribution, and reproduction in any medium, provided the original work is properly cited.

Background. Depression is a significant contributor to the global burden of disease and affects 350 million people worldwide. Substance use could be the risk factor for depression. Objective. We aim to determine the prevalence and severity of depression and its association with substance use. Methods. A cross-sectional study was conducted on a sample of 650 respondents in Jimma town in March 2014. A multistage stratified sampling method was conducted. Structured questionnaire and Beck's Depression Inventory (BDI-II) scale were used for data collection. Data analysis was done using the SPSS Version 20.0 for Windows. Results. The participation rate of respondents was 590/650 (90.77\%). The proportion of females was 300 (50.9\%). The current prevalence of depression was $171(29.0 \%)$. Based on the BDI-II grading of the severity of depression, 102 (59.6\%) had mild, 56 (32.7\%) had moderate, $13(7.6 \%)$ had severe depression. In the present study, age of 55 years and above [OR $=5.94, \mathrm{CI}: 2.26-15.58$ ], being widowed $[\mathrm{OR}=5.18$, CI: 1.18-22.76], illiterates [OR = 9.06, CI: 2.96-27.75], khat chewing [OR = 10.07, CI: 5.57-18.25], cigarette smoking [OR $=3.15$, CI: 1.51-6.58], and shisha usage [OR $=3.04$, CI: 1.01-9.19] were significantly and independently associated with depression. Conclusion. The finding depicted that depression was a moderate public health problem. Advanced age, being widowed, illiterate, khat chewing, and cigarette and shisha smocking could be the potential risk factors for depression. Risk reduction is recommended.

\section{Introduction}

World Health Organization (WHO) has reported that about 450 million people worldwide suffer from mental illness and one in four people meets criteria of mental illness at some point in their life $[1,2]$. Among the mental disorders, depression is a disease of the global burden affecting 350 million people worldwide [3]. A study conducted on adult populations of USA reported that lifetime prevalence of major depressive disorder was $16.2 \%$ and 12 -month prevalence was 6.6\% [4]. Surveys conducted in 16 European countries found that $27 \%$ of adult Europeans are affected by depression: at least one mental disorder in a 12 -month period $[5,6]$. The burden of the disease is higher by $50 \%$ in females than in males [7]. The prevalence of depression in low and middle income countries (LMIC) ranged from 11.1 to $53 \%$.
The burden is highest in Afghanistan, Middle East, and North and Sub-Saharan African countries [8]. It was reported that the prevalence of depression in Ethiopia is 9.1\% [9].

Depression disorder presents with depressed mood, loss of interest or pleasure, decreased energy, feelings of guilt or low self-worth, disturbed sleep or appetite, poor concentration, problem of thinking and making decisions, and, in severe stages, recurring thoughts of death or suicide [10]. Depending on the number and severity of symptoms, a depressive episode can be categorized as mild, moderate, or severe. An individual with a mild depressive episode will have some difficulties in continuing with ordinary work and social activities but will probably not cease to function completely. On the other hand, it is very unlikely that the individual with severe depressive episode will be able to continue with social, work, or domestic activities, except to a very limited 
extent. As for moderate depression, the individual would normally have more than the five symptoms that are needed to make the diagnosis of depression. Moderate episodes have a severity that is intermediate between mild and severe depressions [11].

Depression has many possible causes, including mood disturbance, genetic vulnerability, chronic stressful life, use of psychoactive substances, and medical problems. It is believed that several of these forces interact to bring depression $[10,11]$.

Areas in the brain that are affected in cases of depression are the prefrontal cortex, cingulated gyrus, amygdala, hippocampus, thalamus, and hypothalamus. These brain regions are involved in the regulation of motivation, eating, sleeping, energy level, circadian rhythm, and responses to rewarding and aversive stimuli, which are all abnormal in depressed people [12].

Neurotransmitters that are depleted in patients with depression are serotonin that helps regulate sleep, appetite, and mood and inhibits pain. Reduced serotonin secretion is recorded in patients with depression [13]. Norepinephrine triggers anxiety and is involved in some types of depression. It determines motivation and reward. Norepinephrine and serotonin (5-HT) modulate subcortical and cortical functions that their shortage in states of depression and anxiety contributes to abnormalities in sleep, concentration, attention and memory, arousal states, appetite, and libido [14]. Furthermore, their modulation of the cortical-hippocampalamygdala pathways regulates responses to aversive, stressful, and fearful experience along with modulation of the affective aspects of memory [15].

Several studies confirmed that major depression is associated with a state of reduced dopamine and treated with monoamine oxidase inhibitors [16]. Problems in dopamine secretion have been associated with psychosis, a severe form of distorted thinking, hallucinations, or delusions. Dopamine is thought to play a role during substance abuse [17].

Psychoactive substance use, such as khat (Catha edulis), alcohol, and tobacco have become the rising risk factors for major mental health problems worldwide [18]. Khat (Catha edulis), which is commonly used in the study area, contains a psychoactive substance, cathinone, which stimulates the central nervous system analogous to amphetamine. Its mechanism of action is believed to be mediated via its sympathetic like action in the body [19].

A common side effect of khat use is insomnia, a condition that the users sometimes try to overcome with intake of sedatives or alcohol. The withdrawal symptoms after prolonged khat use are lethargy, mild depression, slight trembling, and recurrent bad moods [20].

Although tobacco contains thousands of chemicals, the main active ingredient that acts in the brain and produces addiction is nicotine. Many of the effects of nicotine are produced through its action on both the central and peripheral nervous systems [21]. Alcohol, a brain depressant and intoxicant, is the most commonly used psychoactive substance by both mentally healthy people and mentally ill people [22].

Depression has severe consequences on the productive human force and social areas which calls the attention of care providers for early diagnosis, proper treatment, and intervention. Although the prevalence of khat use and its physiological and psychosocial effects were studied, there is still limited knowledge on the association between substance use and depression in Jimma town at community level. Therefore, the main aim of the present study is to determine the prevalence and severity of depression and its association with the risk factors such as substance use.

\section{Research Methods}

This cross-sectional, community based study was conducted from 15 February 2014 to 15 March 2014 in Jimma town. The town's total population was estimated to be 130,254. People of $\geq 18$ years of age were included in the study.

Out of thirteen kebeles of Jimma town, six kebeles were selected using a lottery method and 650 households were selected using a systematic random sampling. Once the households were identified, one adult family member was selected randomly using the lottery method. The sample size was calculated using multistage sampling formula; the prevalence rate of depression ( $p$ ) was taken to be $26.3 \%$ from the previous study [23], with the confidence level of $95 \%$ and margin of error of $5 \%$. Contingency of $10 \%$ for the nonresponse rate was added and multiplied by 2 for the design effect assuming that the source population is heterogeneous and multistage sampling was taken.

Beck's Depression Inventory revision II (BDI-II) [24] screening questionnaire has been employed for screening depression and for grading its severity. BDI has a high degree of sensitivity and specificity for detecting depression. BDI scoring was conducted as follows: normal depression (013), mild depression (14-19), moderate depression (20-28), and severe depression (29-63). World Health Organization (WHO) drug addiction questionnaire [25] was adopted and modified to make it relevant to the objectives of the study. The magnitude of khat chewing, alcohol consumption, and cigarette smoking was evaluated using this questionnaire.

To improve the quality of the data, the questionnaire was pretested on 32 randomly selected subjects who were not included in the study samples. Questionnaires were translated from the English language into local language and back-translated to English language for the sake of consistency. A two-day training was given for 6 psychiatric nurses as data collectors. The questionnaires were checked for their completeness during data cleaning and the incomplete ones were discarded. Data analysis was carried out using SPSS Version 20.0 for Windows. Frequency tables were used to summarize categorical data. The associations between predictor and outcome variables were measured using Chi-square test. Multivariate logistic regression analysis was conducted to control confounders and to identify the independent contribution of each variable to the outcome variable.

Ethical clearance was obtained from Jimma University Ethical Review Board. Participants' consent was taken and confidentiality was maintained. 
2.1. Operational Definitions. First, we define substances use: substances that are commonly used in the study site are alcohol, khat, cigarette, and shisha. Second, we define current chewers: they represent the proportion of respondents who were chewing khat within 30 days before the study. Third, we define nonchewers: they represent the proportion of respondents who were not chewing khat within 30 days before the study. Fourth, we define current smokers: They represent the proportion of respondents who were smoking cigarettes within 30 days before the study. Fifth, we define nonsmokers: they represent the proportion of respondents who were not smoking cigarettes within 30 days before the study. Sixth, we define current alcohol users: they represent the proportion of respondents who were drinking alcohol (beer, whisky, local araki, or gin) within 30 days before the study. Seventh, we define lifetime drinkers: they represent the proportion of respondents who had ever drunk alcohol in their lifetime. Eighth, we define non-alcohol users: they represent the proportion of respondents who were not drinking alcohol within 30 days before the study. Shisha is an oriental tobacco pipe with a long, flexible tube connected to a container, where the smoke is cooled by passing through water. Shisha smoking, also called hookah, water pipe, or hubble-bubble smoking, is a way of smoking tobacco, sometimes mixed with fruit or molasses sugar, through a bowl and hose or tube.

\section{Results}

Among 650 respondents, the participation rate was 590 (90.8\%). The current prevalence of depression was 171 (29.0\%). According to BDI-II grading scale, 102 (17.3\%) participants had mild depression, 56 (9.5\%) participants had moderate depression, and $13(2.2 \%)$ participants had severe depression, as presented in Figure 1. The magnitude of depression increases with age (Table 1). The prevalence of depression increases to $56.4 \%$ as the age advances above 55 years. Age above 55 years is 5.9 times more likely to have depression than lower age groups.

As per gender, in comparison with males, significantly larger proportion, $90(52.6 \%)$, of females had depression $(\mathrm{AOR}=2.43 ; 95 \% \mathrm{CI}: 1.43,4.13)$. The highest prevalence of depression was recorded among widows (85.0\%) and illiterates (64.4\%) as presented in Tables 1 and 3.

Out of the total respondents, 200 (33.9\%) khat chewers, $203(34.4 \%)$ alcohol users, 60 (10.2\%) cigarette smokers, and $22(3.7 \%)$ shisha users were recorded. One hundred four $(52.0 \%)$ khat chewers, 38 (63.3\%) cigarette smokers, 75 (36.9\%) alcohol users, and 15 (68.2\%) shisha smokers had depression episodes. There was a significant association between depression and substance use $(p<0.05)$ as shown in Tables 2 and 3.

Those sociodemographic and substance use related variables that have shown a significant association with depression episodes were tested by multivariate logistic regression analysis. Age, sex, marital status, educational status, khat chewing, cigarette smoking, and shisha usage were found to be the risk factors for depression as presented in Table 3. The logistic regression model revealed that the odds of developing

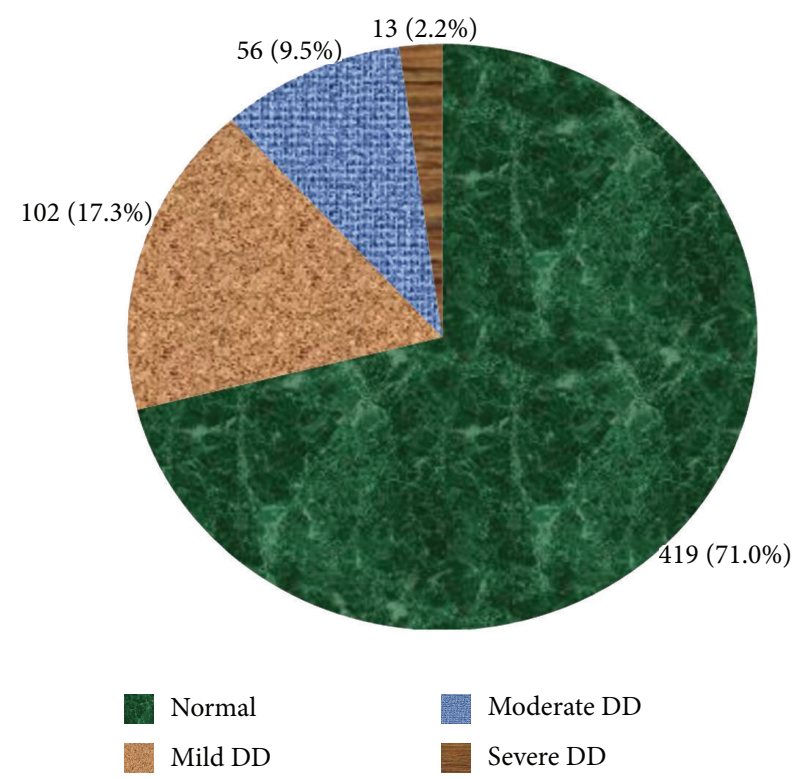

FIGURE 1: Severity of depression disorder in Jimma town, Southwest Ethiopia $(n=590)$. According to Beck's Depression Inventory, cutoff value $\leq 13$ is normal; score of $14-19$ is mild depression; score of 20-28 is moderate depression; score of 29-63 is severe depression. Four hundred nineteen participants were normal and $29 \%$ had depression, out of which $17.3 \%$ had mild depression, $9.5 \%$ had moderate depression, and $2.2 \%$ had severe depression.

depression for 55 years of age and above was as follows: AOR $=5.94 ; 95 \%$ CI: 2.26-15.58. Regarding marital status, widowed individuals were five times more likely to develop depression in comparison with the singles $(\mathrm{AOR}=5.18$; 95\% CI: $1.18-$ 22.76). Illiterate individuals were nine times more likely to develop depression as compared to educated people ( $\mathrm{AOR}=$ 9.06; 95\% CI: 2.96-27.75).

Similarly, khat chewers had tenfold risk of developing depression as compared to nonchewers (AOR $=10.07 ; 95 \%$ CI: 5.57-18.25). Cigarette smokers were approximately three times more likely to develop depression compared to nonsmokers (AOR $=3.15$; 95\% CI: 1.51-6.58) and shisha users had threefold higher risk for having depression compared to nonshisha users (AOR $=3.04 ; 95 \% \mathrm{CI}$ : 1.01-9.19).

\section{Discussion}

Burden of depression poses a substantial public health challenge. In the present study, the current prevalence of depression in the community was $29 \%$. This result is in agreement with the study done in Uganda which has reported prevalence of depression of $29.3 \%$ [26]. A slightly lower prevalence of depression compared to the current finding has been reported by studies conducted in Ethiopia and France: $26.3 \%$ [27] and 26.5\% [28], respectively. A much lower prevalence of depression was reported in studies conducted in South Africa and Malaysia: 9.7\% [29] and 6.3\% [30], respectively. A much higher prevalence of depression, $54.5 \%$, was reported in a study conducted in Nigeria [31]. The possible explanation for the higher prevalence of depression 
TABLE 1: Association between depression and sociodemographic variables in Jimma town, Southwest Ethiopia $(n=590)$.

\begin{tabular}{|c|c|c|c|c|c|c|}
\hline \multirow{2}{*}{ Variables } & & \multicolumn{3}{|c|}{ Depression } & \multirow[b]{2}{*}{$\chi^{2}$} & \multirow[b]{2}{*}{$p$ value } \\
\hline & & $\begin{array}{c}\text { Total, } n=590 \\
N(\%)\end{array}$ & $\begin{array}{c}\text { Yes, } n=171 \\
n(\%)\end{array}$ & $\begin{array}{c}\text { No, } n=419 \\
n(\%)\end{array}$ & & \\
\hline \multirow{2}{*}{ Sex } & Male & $290(49.1)$ & $81(27.9)$ & $209(72.1)$ & & \\
\hline & Female & $300(50.9)$ & $90(30.0)$ & $210(70.0)$ & 31.00 & 0.001 \\
\hline \multirow{5}{*}{ Age } & $18-24$ & $183(63.1)$ & $33(18.0)$ & $150(82.0)$ & \multirow{5}{*}{36.46} & \multirow{5}{*}{0.000} \\
\hline & $25-34$ & $188(31.9)$ & $48(24.5)$ & $140(74.5)$ & & \\
\hline & $35-44$ & $102(17.3)$ & $33(32.4)$ & $69(67.6)$ & & \\
\hline & $45-54$ & $62(10.5)$ & $26(41.9)$ & $36(58.1)$ & & \\
\hline & $\geq 55$ & $55(9.3)$ & $31(56.4)$ & $24(43.6)$ & & \\
\hline \multirow{4}{*}{ Marital status } & Single & $242(41.0)$ & $61(25.2)$ & $181(74.8)$ & \multirow{4}{*}{38.59} & \multirow{4}{*}{0.000} \\
\hline & Married & $312(52.9)$ & $84(23.9)$ & $228(73.1)$ & & \\
\hline & Divorced & $16(2.7)$ & $9(56.2)$ & $7(43.8)$ & & \\
\hline & Widowed & $20(3.4)$ & $17(85.0)$ & $3(15.0)$ & & \\
\hline \multirow{6}{*}{ Occupation } & Merchant & $213(36.1)$ & $51(23.9)$ & $162(76.1)$ & \multirow{6}{*}{36.06} & \multirow{6}{*}{0.000} \\
\hline & Employed & $61(10.3)$ & $21(34.4)$ & $40(65.6)$ & & \\
\hline & Unemployed & $56(9.5)$ & $18(32.1)$ & $38(67.9)$ & & \\
\hline & Housewife & $134(22.7)$ & $55(41.0)$ & $79(59.0)$ & & \\
\hline & Students & $102(17.3)$ & $15(13.8)$ & $94(86.2)$ & & \\
\hline & Others* & $24(4.1)$ & $11(64.7)$ & $6(35.3)$ & & \\
\hline \multirow{6}{*}{ Educational status } & Illiterate & $45(7.6)$ & $29(64.4)$ & $16(35.6)$ & \multirow{6}{*}{29.47} & \multirow{6}{*}{0.000} \\
\hline & $1^{\circ}$ School & $140(23.7)$ & $49(35.0)$ & $91(65.0)$ & & \\
\hline & $2^{\circ}$ School & $207(35.1)$ & $50(27.1)$ & $151(72.9)$ & & \\
\hline & Certificate & $38(6.4)$ & $11(28.9)$ & $27(71.1)$ & & \\
\hline & Diploma & $84(14.2)$ & $12(14.3)$ & $72(85.7)$ & & \\
\hline & Degree plus & $76(12.9)$ & $14(18.4)$ & $62(81.6)$ & & \\
\hline
\end{tabular}

${ }^{*}$ Farmers, pension.

TABLE 2: Association between depression and substance use in Jimma town, Southwest Ethiopia $(n=590)$.

\begin{tabular}{|c|c|c|c|c|c|c|}
\hline \multirow[b]{2}{*}{ Variables } & & \multicolumn{3}{|c|}{ Depression } & \multirow[b]{2}{*}{$\chi^{2}$} & \multirow[b]{2}{*}{$p$ value } \\
\hline & & $\begin{array}{c}\text { Total, } n=590 \\
N(\%)\end{array}$ & $\begin{array}{c}\text { Yes, } n=171 \\
n(\%)\end{array}$ & $\begin{array}{c}\text { No, } n=419 \\
n(\%)\end{array}$ & & \\
\hline \multirow{2}{*}{ Current khat chewing } & Yes & $200(33.9)$ & $104(52.0)$ & $96(48.0)$ & \multirow{2}{*}{77.88} & \multirow{2}{*}{0.000} \\
\hline & No & $390(66.1)$ & $67(17.2)$ & $323(82.8)$ & & \\
\hline \multirow{2}{*}{ Current cigarette smoking } & Yes & $60(10.2)$ & $38(63.3)$ & $22(36.7)$ & \multirow{2}{*}{38.29} & \multirow{2}{*}{0.000} \\
\hline & No & $530(89.8)$ & $133(25.1)$ & $397(74.9)$ & & \\
\hline \multirow{2}{*}{ Current alcohol intake } & Yes & $203(34.4)$ & $75(36.9)$ & $128(63.1)$ & \multirow{2}{*}{9.53} & \multirow{2}{*}{0.002} \\
\hline & No & $387(65.6)$ & $96(24.8)$ & $291(75.2)$ & & \\
\hline \multirow{2}{*}{ Current shisha use } & Yes & $22(3.7)$ & $15(68.2)$ & $7(31.8)$ & \multirow{2}{*}{17.06} & \multirow{2}{*}{0.000} \\
\hline & No & $568(96.3)$ & $156(27.5)$ & $412(72.5)$ & & \\
\hline
\end{tabular}

disorder in the present study could be associated with the high production distribution and consumption of khat. Khat is grown abundantly in Jimma area. Many people chew khat in this place for different purposes. In most cases, khat chewing is accompanied by coffee drinking, cigarette smoking, and shisha usage and after these substances people used to drink alcohol to reduce the excitatory effect of khat and nicotine. Regular usage of all these substances could be the potential predisposing factors for depression.
In the current study, advanced age is strongly associated with the occurrence of depression and the result of this study is consistent with other previous findings conducted in USA [32] and Malaysia [30]. Age of 55 years and above was approximately six times more likely to develop depression as compared with age of 18-24 years. This could be due to disturbances of sleep, appetite, and sexual activities and due to an imbalance of neurotransmitters in the brain for nerve impulse transmission as age increases. Depressive 
TABLE 3: Multivariate logistic regression analysis for the association of different variables with depression episode in Jimma town, Southwest Ethiopia $(n=590)$.

\begin{tabular}{|c|c|c|c|c|c|}
\hline Variables & Categories & $\begin{array}{c}\text { Total respondents } \\
n(\%)\end{array}$ & $\begin{array}{c}\text { Depression } \\
\text { episodes } \\
n(\%)\end{array}$ & $\operatorname{AOR}(95 \% \mathrm{CI})$ & $p$ values \\
\hline \multirow{5}{*}{ Age } & $18-24$ & $183(31.0)$ & $131(31.0)$ & 1.00 & \\
\hline & $25-34$ & $188(31.9)$ & $188(31.9)$ & $0.89(0.46-1.73)$ & 0.732 \\
\hline & $35-44$ & $102(17.3)$ & $102(17.3)$ & $1.55(0.70-3.41)$ & 0.281 \\
\hline & $45-54$ & $62(10.5)$ & $62(10.5)$ & $3.04(1.24-7.41)$ & 0.015 \\
\hline & $55+$ & $55(9.3)$ & $55(9.3)$ & $5.94(2.26-15.58)$ & 0.000 \\
\hline \multirow{2}{*}{ Sex } & Male & $290(49.2)$ & $290(49.2)$ & 1.00 & \\
\hline & Female & $300(50.9)$ & $300(50.8)$ & $2.43(1.43-4.13)$ & 0.001 \\
\hline \multirow{4}{*}{ Marital status } & Single & $242(41.0)$ & $242(41.0)$ & 1.00 & \\
\hline & Married & $312(52.9)$ & $312(52.9)$ & $0.75(0.42-1.35)$ & 0.335 \\
\hline & Divorced & $16(2.7)$ & $16(2.7)$ & $1.49(0.41-5.48)$ & 0.547 \\
\hline & Widowed & $20(3.4)$ & $20(3.4)$ & $5.18(1.18-22.77)$ & 0.029 \\
\hline \multirow{6}{*}{ Education } & Illiterate & $45(7.6)$ & $45(7.6)$ & $9.06(2.96-27.75)$ & 0.000 \\
\hline & Primary & $140(23.7)$ & $140(23.7)$ & $4.13(1.70-10.08)$ & 0.002 \\
\hline & Secondary & $207(35.1)$ & $207(35.1)$ & $3.14(1.38-7.12)$ & 0.006 \\
\hline & Certificate & $38(6.4)$ & $38(6.4)$ & $4.36(1.41-13.43)$ & 0.010 \\
\hline & Diploma & $84(14.2)$ & $84(14.2)$ & $1.00(0.37-2.74)$ & 1.000 \\
\hline & Degree+ & $76(12.9)$ & $76(12.9)$ & 1.00 & \\
\hline \multirow{2}{*}{ Current khat chewing } & Yes & $200(33.9)$ & $104(52 \%)$ & $10.07(5.57-18.25)$ & 0.000 \\
\hline & No & $390(66.1)$ & $67(17.2 \%)$ & 1.00 & \\
\hline \multirow{2}{*}{ Current cigarette smoking } & Yes & $60(10.2)$ & $38(63.3 \%)$ & $3.15(1.51-6.58)$ & 0.002 \\
\hline & No & $530(89.8)$ & $133(25.1 \%)$ & 1.00 & \\
\hline \multirow{2}{*}{ Current alcohol intake } & Yes & $203(34.4)$ & $75(36.9 \%)$ & $1.05(0.63-1.76)$ & 0.856 \\
\hline & No & $387(65.6)$ & $96(24.8 \%)$ & 1.00 & \\
\hline \multirow{2}{*}{ Current shisha use } & Yes & $22(3.7)$ & $15(68.2 \%)$ & $3.04(1.01-9.19)$ & 0.049 \\
\hline & No & $568(96.3)$ & $156(27.5 \%)$ & 1.00 & \\
\hline
\end{tabular}

$1.00=$ reference categories. All variables were adjusted to differentiate between predictors and confounders.

symptoms are significantly higher among elders above the age of 55 years. The possible explanation is that as the age advances, several problems related to aging come into picture including deterioration of body functions and hormonal secretions and metabolic activities, decreased quality of life, and higher mortality from comorbid medical conditions which contribute to the development of depression.

In the present study, females were found to be twice more vulnerable to depression than males. This report is consistent with a study conducted in Turkey [33]. This could be due to a low social and economic status, cultural discrimination, the affective nature of females response to stressful life, and hormonal changes during puberty; postpartum and postmenopausal periods and taking contraceptive pills have been incriminated as possible factors for the higher prevalence of depression among women.

According to the present findings, depression was significantly associated with educational status. The prevalence of depression was nine times higher among illiterates compared to educated samples. The result is in agreement with studies conducted in South Africa [29] and Turkey [33]. The possible explanation for this could be the fact that individuals with low socioeconomic and educational status were given less value to their self-esteem and live a stressful life as compared with educated individuals. In addition, educated people have better understanding of the risk factors of depression compared to illiterates.

In this study, depression has shown a significant association with marital status. Widowed individuals were five times more likely to develop depression as compared to single individuals. The result of this report was in line with the study conducted in Ethiopia [27, 34, 35]. This could be due to the fact that the loss of a spouse or lovers has been identified as one of the most stressful life events, requiring more psychological therapy compared to many others.

Depression was significantly associated with khat chewing. The probability of developing depression episodes among khat chewers is tenfold higher than that among nonchewers. This result is consistent with the study conducted in Jimma University [18, 23] and with WHO expert analysis [36]. Some authors propose that depression episodes disappeared during khat chewing sessions [22]. But these depressive symptoms 
crop up on cessation of khat use. This might be due to the fact that khat contains psychoactive chemicals cathinone and cathine that have amphetamine like action in the brain which activates the release of monoaminergic neurotransmitters such as dopamine [37] in the limbic system, resulting in reward sensations but after the cessation of khat, it leads to depression.

The result of the present study indicated that depression shows a significant association with current cigarette smoker. This result demonstrates that smokers have developed depression symptom three times greater than nonsmokers. The present finding is in agreement with the study conducted by Pasco et al. [38]. However, other works in literature explained that depression and smoking show bidirectional relationship [39]. Substance use increases the risk of major depressive disorder [40]. Persons with major depression tend to abuse substances and have difficulties when they try to stop. There are thousands of chemicals other than nicotine present in cigarette smoke, of which one or several may affect mood in the same way as a group of antidepressant medications called monoamine oxidase inhibitors or (MAOIs) does [41]. These MAOIs effectively increase levels of specific neurotransmitters involved in the regulation of mood. Smoking, therefore, may be one way for depressed individuals to alleviate depressive symptoms.

\section{Conclusion}

To sum up, the magnitude of depression episodes recorded so far was found to be a moderate public health problem. The strongest association was recorded in the present study between depressive episodes and substance use. Chronic regular use of a psychoactive plant, khat, could be a potential risk factor. Khat chewing is accompanied by cigarette smoking and alcohol drinking. Avoidance of risk factors for depression is such a commendable preventive measure. Psychological and pharmacological therapies are equally important as well.

\section{Conflict of Interests}

The authors declare that they have no conflict of interests.

\section{Authors' Contribution}

All the authors contributed equally to the conception and design of the study, analysis and interpretation of the data, and drafting the paper. Finally, they all approved the final version.

\section{Acknowledgments}

The authors are grateful to Jimma University for its support. The authors also thank all the data collectors and the study participants who have kindly given them the necessary information.

\section{References}

[1] World Health Organization, Promoting Mental Health: Concepts Emerging Evidence Practice, Summary Report, World Health Organization, Geneva, Switzerland, 2004.

[2] World Health Organization, The World Health Report: 2001: Mental Health: New Understanding, New Hope, World Health Organization, Geneva, Switzerland, 2001.

[3] World Health Organization, The World Health Report 2002Reducing Risks, Promoting Healthy Life, World Health Organization, Geneva, Switzerland, 2002.

[4] R. C. Kessler, P. Berglund, O. Demler et al., “The epidemiology of major depressive disorder: results from the national comorbidity survey replication (NCS-R)," The Journal of the American Medical Association, vol. 289, no. 23, pp. 3095-3105, 2003.

[5] T. Fryers, T. Brugha, Z. Morgan et al., "Prevalence of psychiatric disorder in Europe: the potential and reality of meta-analysis," Social Psychiatry and Psychiatric Epidemiology, vol. 39, no. 11, pp. 899-905, 2004.

[6] E. S. Paykel, T. Brugha, and T. Fryers, "Size and burden of depressive disorders in Europe," European Neuropsychopharmacology, vol. 15, no. 4, pp. 411-423, 2005.

[7] H.-U. Wittchen and F. Jacobi, "Size and burden of mental disorders in Europe-a critical review and appraisal of 27 studies," European Neuropsychopharmacology, vol. 15, no. 4, pp. 357-376, 2005.

[8] D. Akena, J. Joska, E. A. Obuku, T. Amos, S. Musisi, and D. J. Stein, "Comparing the accuracy of brief versus long depression screening instruments which have been validated in low and middle income countries: a systematic review," BMC Psychiatry, vol. 12, article 187, 2012.

[9] S. Hailemariam, F. Tessema, M. Asefa, H. Tadesse, and G. Tenkolu, "The prevalence of depression and associated factors in Ethiopia: findings from the National Health Survey," BMC International Journal of Mental Health Systems, vol. 6, article 3, 2012.

[10] M. Marcus, M. T. Yasamy, M. van Ommeren, D. Chisholm, and S. Saxena, "Depression: a global public health concern," in Proceedings of the 65th World Health Assembly, World Health Organization, Geneva, Switzerland, May 2012, http://www.who .int/mediacentre/events/2012/wha65/journal/.

[11] World Health Organization, The Global Burden of Disease 2004 Update, 2008, http://www.who.int/healthinfo/global_ burden_disease/GBD_report_2004update_full.pdf.

[12] E. J. Nestler, M. Barrot, R. J. DiLeone, A. J. Eisch, S. J. Gold, and L. M. Monteggia, "The neurobiology of depression," Neuron, vol. 34, no. 1, pp. 13-25, 2002.

[13] M. J. Owens and C. B. Nemeroff, "Role of serotonin in the pathophysiology of depression," Clinical Chemistry, vol. 40, no. 2, pp. 288-295, 1994.

[14] D. S. Charney, "Monoamine dysfunction and the pathophysiology and treatment of depression," Journal of Clinical Psychiatry, vol. 59, supplement 14, pp. 11-14, 1998.

[15] K. J. Ressler and C. B. Nemeroff, "Role of serotonergic and noradrenergic systems in the pathophysiology of depression and anxiety disorders," Depression and Anxiety, vol. 12, supplement 1, pp. 2-19, 2000.

[16] B. W. Dunlop and C. B. Nemeroff, "The role of dopamine in the pathophysiology of depression," Archives of General Psychiatry, vol. 64 , no. 3, pp. 327-337, 2007. 
[17] A. S. Brown and S. Gershon, "Dopamine and depression," Journal of Neural Transmission/General Section, vol. 91, no. 2-3, pp. 75-109, 1993.

[18] Y. Gelaw and A. Haile-Amlak, "Khat chewing and its sociodemographic correlates among the staff of Jimma University," Ethiopian Journal of Health Development, vol. 18, no. 3, pp. 179184, 2005.

[19] I. Dhaifalah and J. Šantavý, "Khat habit and its health effect: a natural amphetamine," Biomedical Papers, vol. 148, no. 1, pp. 11$15,2004$.

[20] E. B. Erica, G. Falkay, and A. Gabor, "Khat a controversial plant," The Middle Europian Journal of Medicine, vol. 121, pp. 604-614, 2009.

[21] R. Jain and K. Mukherjee, "Biological Basis of nicotine addiction," Indian Journal of Pharmacology, vol. 35, no. 5, pp. 281-289, 2003.

[22] K. Graham, A. Massak, A. Demers, and J. Rehm, "Does the association between alcohol consumption and depression depend on how they are measured?" Alcoholism: Clinical and Experimental Research, vol. 31, no. 1, pp. 78-88, 2007.

[23] D. Tekalign, M. Andualem, and T. Markos, "Khat chewing and mental distress: a community based study, Jimma Town, Southwest Ethiopia," Ethiop Journal of Health Sciences, vol. 21, no. 1, pp. 37-45, 2011.

[24] A. T. Beck, R. A. Steer, R. Ball, and W. Ranieri, "Comparison of beck depression inventories-IA and-II in psychiatric outpatients," Journal of Personality Assessment, vol. 67, no. 3, pp. 588597, 1996.

[25] R. G. Smart, P. H. Hughes, L. D. Johnston et al., "A methodology for student drug-use surveys," World Health Organization Offset Publication 50, WHO, Geneva, Switzerland, 1983.

[26] E. Kinyanda, J. Tugumisirize, and S. Ndyanabangi, "Poverty, life events and the risk for depression in Uganda," Society of Psychiatric Epidemiology, vol. 46, no. 1, pp. 35-44, 2011.

[27] S. Mogga, M. Prince, A. Alem et al., "Outcome of major depression in Ethiopia," British Journal of Psychiatry, vol. 189, pp. 241-246, 2006.

[28] K. Ritchie, S. Artero, I. Beluche et al., "Prevalence of DSMIV psychiatric disorder in the French elderly population," The British Journal of Psychiatry, vol. 184, no. 2, pp. 147-152, 2004.

[29] M. Tomlinson, A. T. Grimsrud, D. J. Stein, D. R. Williams, and L. Myer, "The epidemiology of major depression in South Africa: results from the South African Stress and Health study," South African Medical Journal, vol. 99, no. 5, pp. 368-373, 2009.

[30] M. Sherina, R. L. Sidik, M. Aini, and H. Norhidayati, "The prevalence of depression among elderly in an urban area of Selangor, Malaysia," The International Medical Journal, vol. 4, no. 2, pp. 57-67, 2005.

[31] O. M. Aiyelero, H. O. Kwanashie, T. L. Sheikh, and I. M. Hussaini, "Some socio-demographic features of mood disorders presented by patients attending a northern Nigerian tertiary health institution clinic," Journal of Applied Pharmaceutical Science, vol. 1, no. 6, pp. 92-95, 2011.

[32] A. Fiske, J. L. Wetherell, and M. Gatz, "Depression in older adults," Annual Review of Clinical Psychology, vol. 5, pp. 363389, 2009.

[33] M. Topbafl, F. Yaris, G. Can, M. Kapuca, and K. Sayar, “The effect of sociodemographic factors and medical status on depressive symptoms of the inhabitants of nursing home and communitydwelling elders in Trabzon-Turkey," Bulletin of Clinical Psychopharmacology, vol. 14, pp. 57-60, 2012.
[34] N. Deyessa, Y. Berhane, A. Alem, U. Hogberg, and G. Kullgren, "Depression among women in rural Ethiopia as related to socioeconomic factors: a community-based study on women in reproductive age groups," Scandinavian Journal of Public Health, vol. 36 , no. 6, pp. 589-597, 2008.

[35] P. J. Clayton, J. A. Halikas, and W. L. Maurice, “The depression of widowhood," British Journal of Psychiatry, vol. 120, no. 554, pp. 71-77, 1972.

[36] World Health Organization, Promoting Mental Health: Concepts Emerging Evidence Practice, Summary Report, Geneva, Switzerland, 2004.

[37] N. B. Patel, "Mechanism of action of cathinone: the active ingredient of khat (Catha edulis)," East African Medical Journal, vol. 77, no. 6, pp. 329-332, 2000.

[38] J. A. Pasco, L. J. Williams, F. N. Jacka et al., "Tobacco smoking as a risk factor for major depressive disorder: population-based study," British Journal of Psychiatry, vol. 193, no. 4, pp. 322-326, 2008.

[39] N. Breslau, S. P. Novak, and R. C. Kessler, "Psychiatric disorders and stages of smoking," Biological Psychiatry, vol. 55, no. 1, pp. 69-76, 2004.

[40] L. C. Dierker, S. Avenevoli, K. R. Merikangas, B. P. Flaherty, and M. Stolar, "Association between psychiatric disorders and the progression of tobacco use behaviors," Journal of the American Academy of Child \& Adolescent Psychiatry, vol. 40, no. 10, pp. 1159-1167, 2001.

[41] L. S. Covey, A. H. Glassman, and F. Stetner, "Cigarette smoking and major depression," Journal of Addictive Diseases, vol. 17, no. 1, pp. 35-46, 1998. 


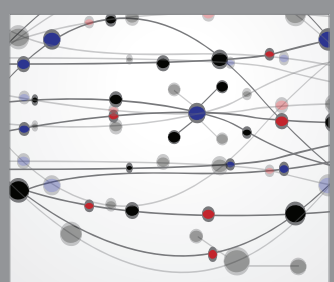

The Scientific World Journal
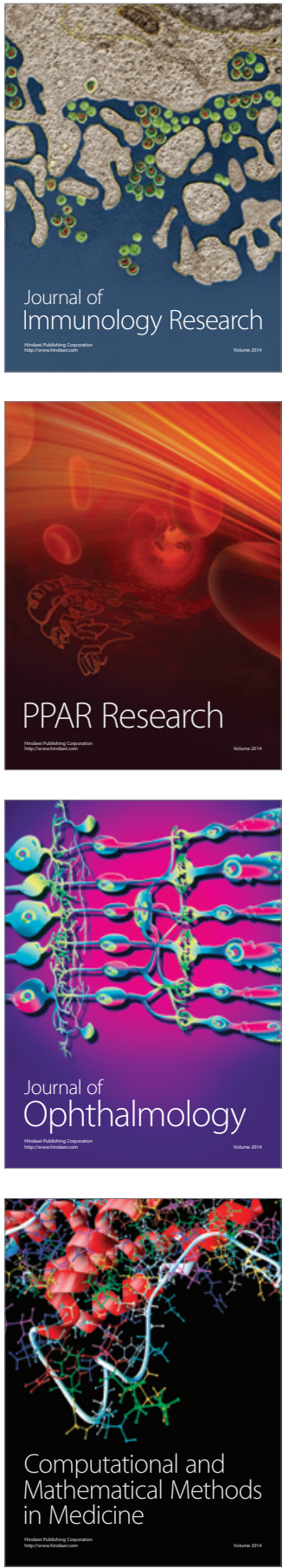

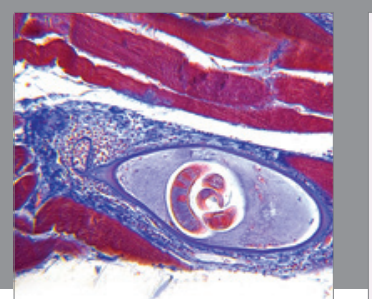

Gastroenterology Research and Practice

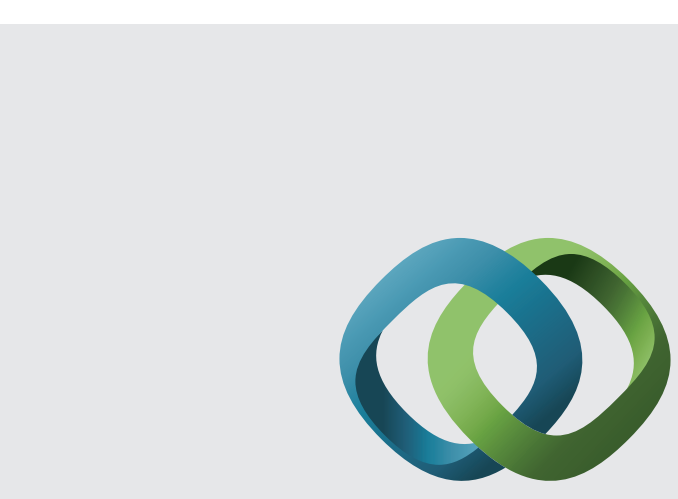

\section{Hindawi}

Submit your manuscripts at

http://www.hindawi.com
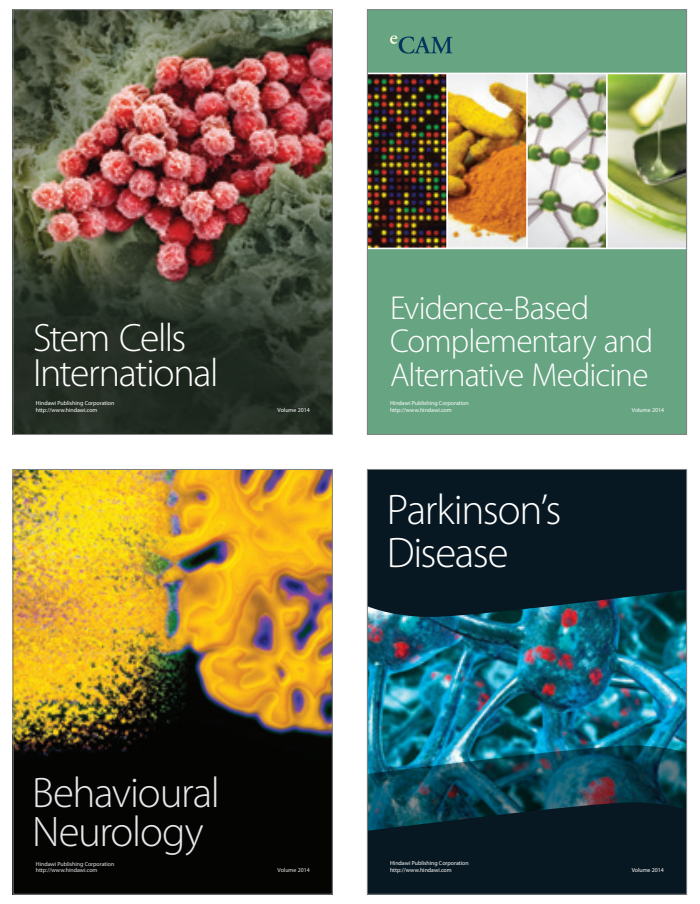
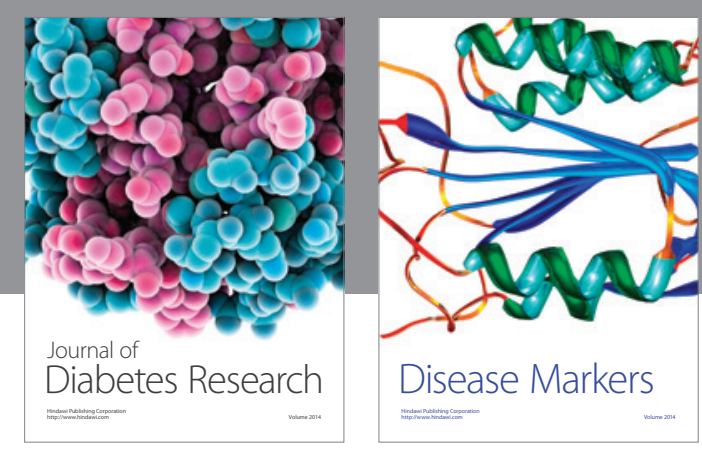

Disease Markers
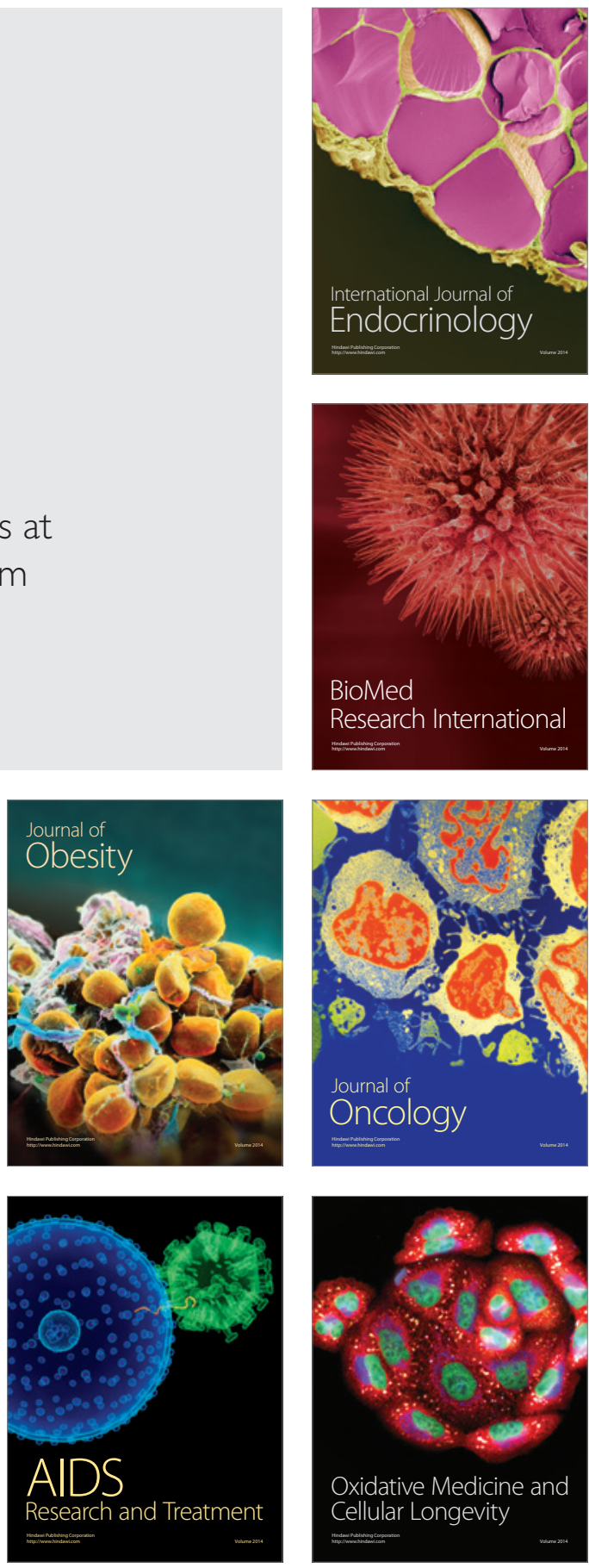